\title{
POSSIBLE IMMUNOLOGICAL BASIS FOR A REDUCTION OF FERTILITY IN CROSS-MATING FOWL WITH JAPANESE QUAIL
}

\author{
L. E. HALEY* AND H. ABPLANALP \\ Department of Poultry Husbandry, University of California, \\ Davis, California 95616
}

(Received 23rd May 1969, revised 26th May 1970)

\begin{abstract}
Summary. Female quail from populations selected for high interspecific fertility when bred with fowl were inseminated half-weekly with fowl semen for periods up to 18 consecutive weeks. At the end of that time, all birds showed a decline in interspecific fertility and the blood plasma of approximately half of the female quail contained antibodies against fowl spermatozoa. The interspecific fertility of these birds was considerably less than that of the birds which did not have antibodies.

In a second experiment, female quail with high interspecific fertility were given an intravenous injection of fowl semen. Their interspecific fertility was approximately $10 \%$ lower than a control group of female quail.
\end{abstract}

\section{INTRODUCTION}

The presence of antibodies against spermatozoa in female blood plasma has been associated with a reduction in fertility in both birds and mammals. McCartney (1923) injected fowl testes into laying hens and thereafter observed a period of relative infertility lasting from 12 to 67 days. Wentworth \& Mellen (1963) found that blood of naturally mated fowl hens had higher anti-spermatozoa agglutination titres than those of virgin hens. The same authors found similarly increased titres following repeated artificial insemination of hens, accompanied by shortened duration of fertility (Wentworth \& Mellen, 1964).

A summary of mammalian work (Tyler, 1961) indicates that immunization of females with seminal material results in decreased fertility. In contrast to these findings, Lamoreux (1940) found that fowl hens retained fertility after immunization with spermatozoa although they had attained high antibody titres.

In view of the many positive findings from intraspecific matings concerning antibody formation and lowered fertility in response to repeated insemination, the present study was undertaken to establish whether immunological mechanisms play a rôle in the reduction of fertility between species. Preliminary evidence for the existence of such an immunological mechanism causing reduced inter-

* Present address: Biology Department, Dalhousie University, Halifax, Nova Scotia, Canada. 
specific fertility was found in a selection experiment where quail (Coturnix coturnix japonica) hens were routinely tested for their ability to produce hybrids when inseminated with fowl (Gallus domesticus) semen (Haley, Abplanalp \& Enya, 1966; Haley, 1967). In their studies, selection over fourteen generations resulted in an increase in interspecific fertility of the quail lines. However, in each generation, it was found that repeated insemination of 9- to 10-week-old quail hens with fowl semen resulted in a gradual increase in the incidence of hybrid-zygotes until a maximum was reached after about ten half-weekly inseminations, followed by a decline in fertility in some cases. This decline from the maximum interspecific fertility suggested some immunological response of the quail females against fowl spermatozoa.

\section{MATERIALS AND METHODS}

Interspecific fertility tests were conducted by inseminating quail hens halfweekly with fowl spermatozoa. Eggs were set at weekly intervals and incubated for 7 days before examining them for embryo development. At that time, all eggs which showed well-developed embryos by candling were returned to the incubator and hatched. The remaining eggs were broken out and classified according to the presence or absence of visible cell proliferation or embryo development. The interspecific fertility of female quail was calculated as the percentage of eggs showing some hybrid-zygote development.

The quail hens used in the first experiment were from the twelfth generation of a selection experiment designed to increase the incidence of hybrid zygotes between quail and fowl populations (Haley et al., 1966). In a preliminary fertility test, the interspecific fertility of 240 quail hens was obtained. The $20 \%$ with the highest incidence of hybrid development were selected and used to propagate their populations. Of the remaining hens, all those with less than $10 \%$ hybrid incidence were discarded. The remaining 120 quail hens with intermediate hybrid incidence were set aside for the present study. They were randomly allocated to three insemination schedules as follows:

Group I: half-weekly inseminations over 18 weeks

Group II: half-weekly inseminations for 6 weeks, followed by an interruption of 6 weeks and subsequent half-weekly insemination for a third 6-week period.

Group III: no insemination for 6 weeks, followed by half-weekly inseminations over 12 weeks.

Experimental inseminations in Groups I and II were begun when the quail hens were 22 weeks old, 7 weeks after the preliminary fertility tests were discontinued. In Group III, the lapse in inseminations after preliminary tests lasted 13 weeks, until the hens were 28 weeks old. The fowl males used for the experiment had also been pre-tested for their capacity to produce hybrid fertility with quail, and all those below $20 \%$ fertility were eliminated.

Following the last weekly hatch of hybrids (39th week of age), a blood sample was obtained from surviving quail hens.

The blood was mixed with citrated saline ( $2 \%$ sodium citrate plus $0.5 \%$ sodium chloride) in the ratio $1 \mathrm{ml}$ of saline solution to $2 \mathrm{ml}$ of blood. After 
centrifugation at $1200 \mathrm{rev} / \mathrm{min}$ for $10 \mathrm{~min}$, the plasma was removed by aspiration with a pipette.

The blood plasma of each quail hen was then tested for antibodies against fowl spermatozoa. These tests were conducted on plastic Disposa Trays (Model 96U-CV of the Limbro Chemical Co., New Haven, Conn.) which consist of eight rows of twelve wells. In each well were placed two drops of $1 \%$ saline, two drops of quail plasma, and two drops of a solution of one part mixed fowl semen to ten parts $1 \%$ saline. Agglutination reactions were scored after $10 \mathrm{~min}$ at $75^{\circ} \mathrm{F}$. The tray was then incubated at $100^{\circ} \mathrm{F}$ for $4 \mathrm{hr}$ and again scored for agglutination. Control groups of forty-nine 10-week-old virgin female quail and twenty quail hens which had been mated naturally to quail males for more than a year were similarly tested for the presence of antibodies against fowl spermatozoa.

In a second experiment, quail hens were immunized intravenously against fowl semen. The quail females belonged to the fourteenth generation of the selection experiment already mentioned. Pre-tested quail hens having fertility with fowl in excess of $35 \%$ were divided into two equivalent groups of fifty birds each. One group of hens received injections into the brachial vein on one occasion with $0.5 \mathrm{ml}$ of a solution containing one part of fowl semen to five parts of $1 \%$ saline solution, using a $\frac{1}{2}$-in. 27-G hypodermic needle. In some birds, the vein ruptured and they subsequently received a subcutaneous injection. The second group of fifty hens served as controls and were injected with saline solution. All quail hens were then inseminated with fowl semen for 8 consecutive weeks and fertility was determined as previously described.

\section{RESULTS}

\section{Experiment 1}

Quail hens of Group I which received thirty-six half-weekly inseminations over a period of 18 weeks showed a gradual decline from about $50 \%$ to $20 \%$ in their average cross-fertility with fowl semen (Text-fig. 1-all birds). These results are in accordance with previous findings (Haley et al., 1966) that fertility increases initially, followed by a decline.

Agglutination tests of Group I quail plasma, conducted at the end of the experimental fertility tests, showed that about half the hens had circulating antibodies against fowl semen. The average interspecific fertility of these reactors was then compared in retrospect with the fertility of hens whose plasma did not contain antibodies. The results of this analysis are also shown in Text-fig. 1 and demonstrate that the group with terminal agglutination of semen had lower fertility than hens with no agglutination. These differences were apparently established early in the experiment, but not as early as the preliminary fertility tests. However, fertility in the last 3 weeks of the experimental test no longer correlated with the terminal agglutination reaction. It must be concluded, therefore, that factors other than serum antibodies played a rôle in the terminal decline in fertility.

Similar results were obtained in Group II hens (Text-fig. 2) where inseminations were made for 6 weeks, interrupted for 6 weeks and then recommenced 
for a final 6-week period. Average fertility declined much as it did in Group I with uninterrupted inseminations. Again, hens whose plasma showed no terminal agglutination reactions with fowl semen had relatively high fertility. This difference in hybrid fertility became more distinct as the fertility tests progressed, and persisted to the end. Hens without agglutination reactions

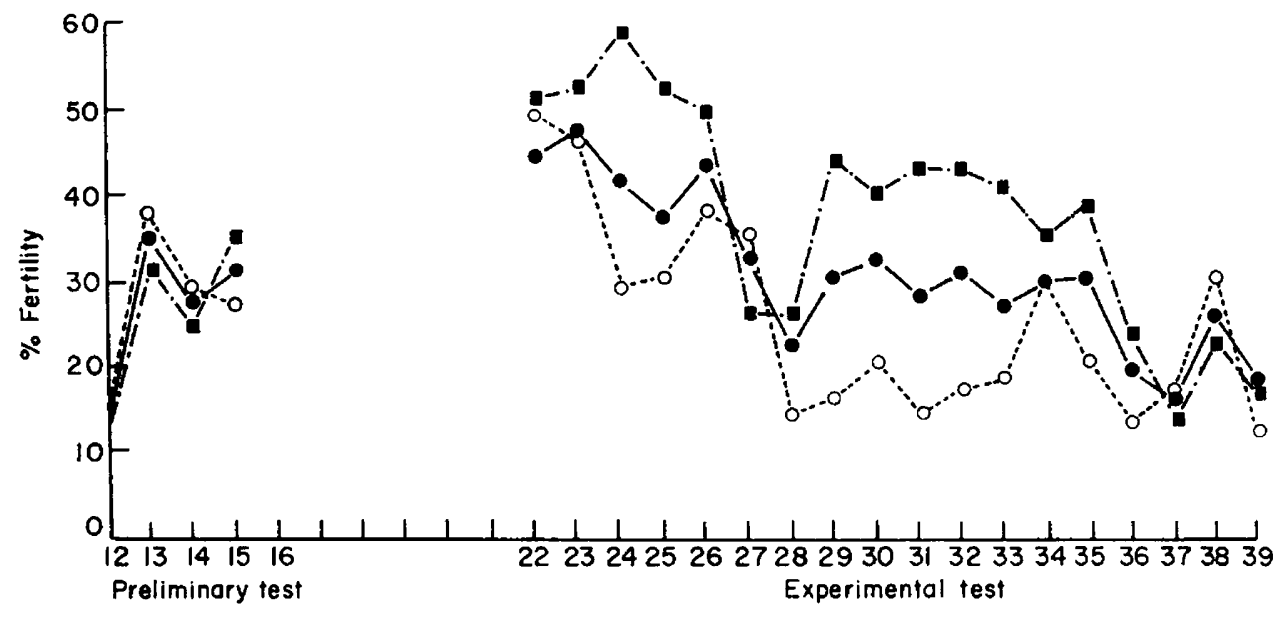

Age of hens (weeks)

TExT-FIG. 1. Interspecific fertility of female quail-Group I, continuous insemination.

, All birds; 0 , birds with antibodies; $\square$, birds without antibodies.

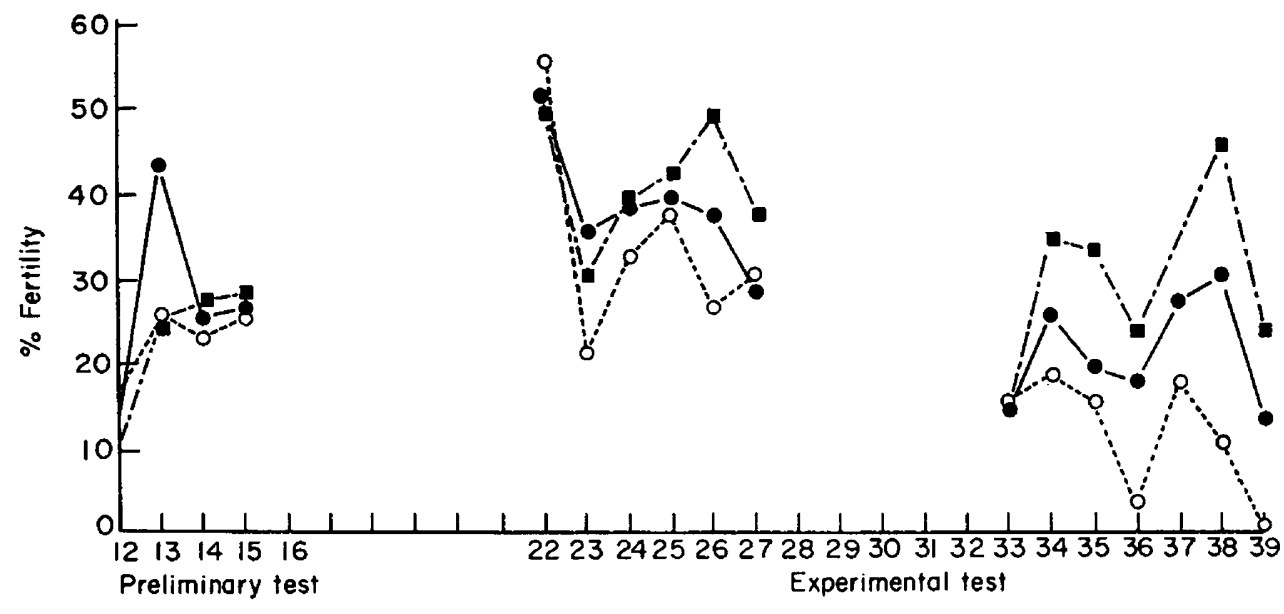

Age of hens (weeks)

TEXT-FIG. 2. Interspecific fertility of female quail-Group II, interrupted insemination.

, All birds; $O$, birds with antibodies; $\square$, birds without antibodies.

maintained fertility with fowl at fairly high levels throughout, while those which developed antibody reactors approached complete infertility towards the end of the experimental fertility tests.

Hens belonging to Group III of this experiment remained uninseminated for 13 weeks following the preliminary tests. They then received twenty-four half- 
weekly inseminations, coinciding in time with the last 12 weeks of the other test groups. The pattern of fertility observed for Group III (Text-fig. 3) is distinctively different from that of the other two groups. Starting at a low level of about

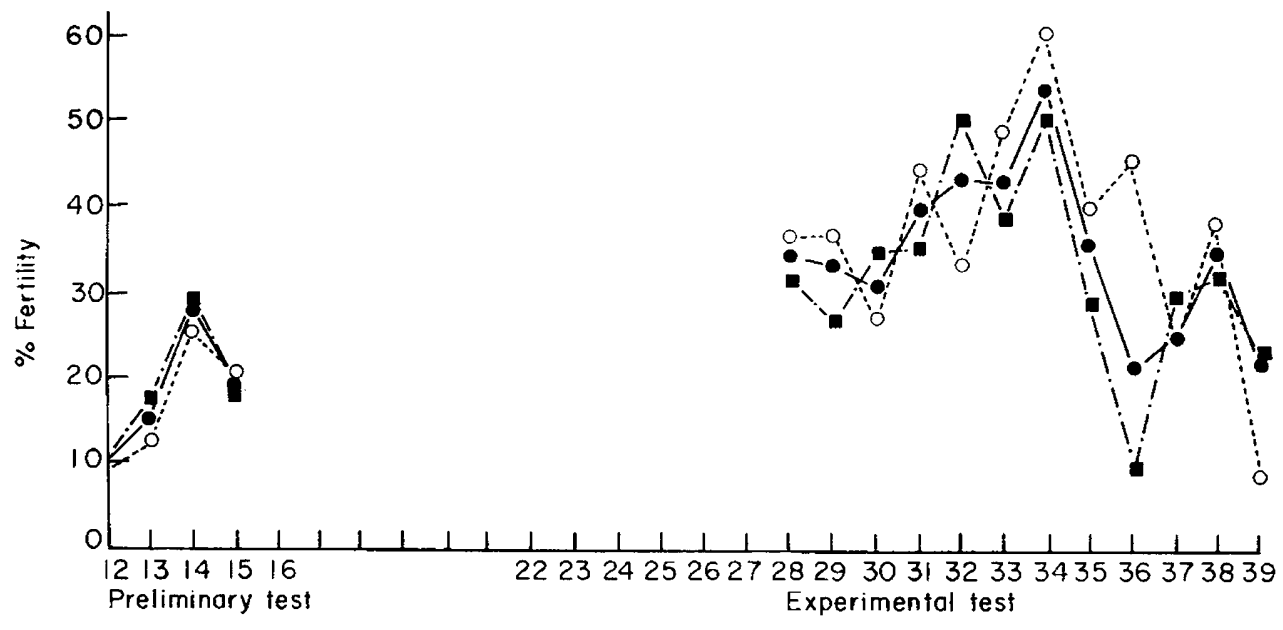

Age of hens (weeks)

TExT-Fic. 3. Interspecific fertility of female quail-Group III, delayed insemination.

0 , All birds; $O$, birds with antibodies; $\boldsymbol{E}$, birds without antibodies.

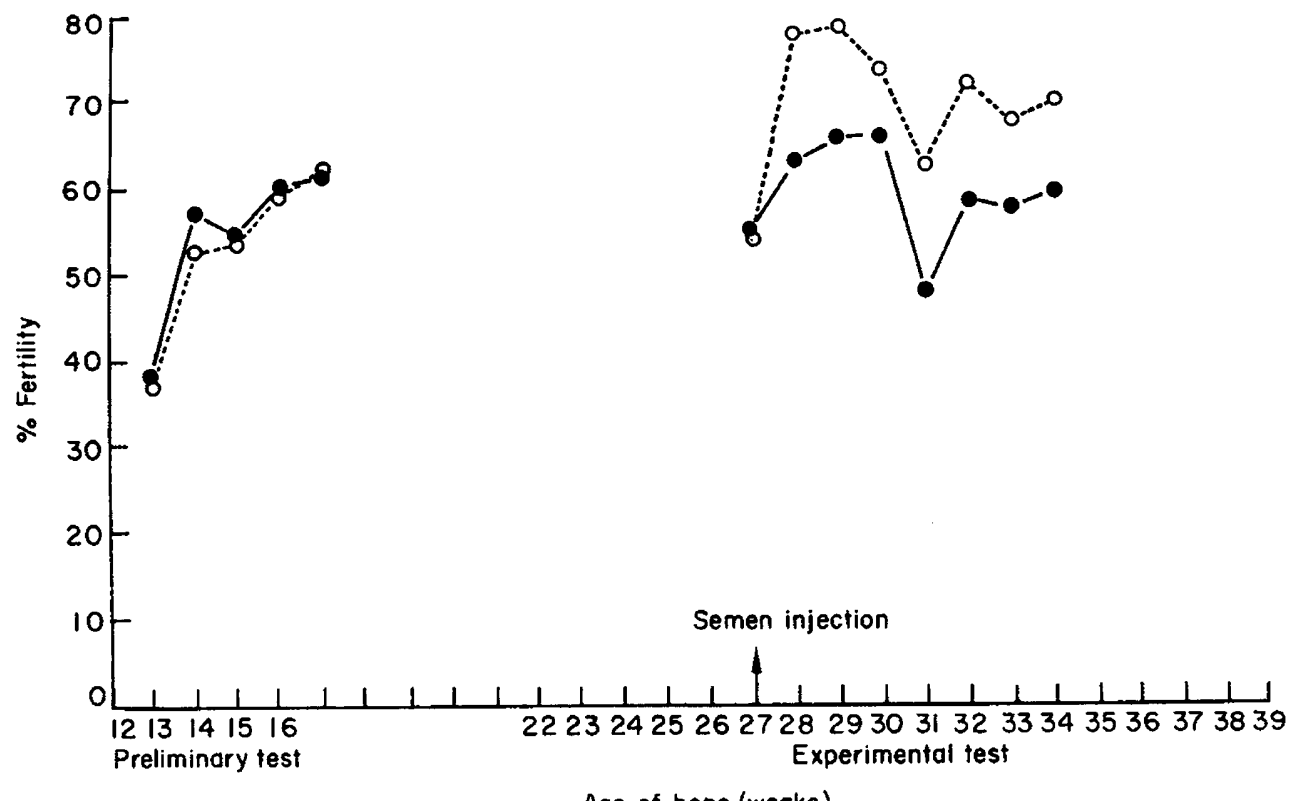

Age of hens (weeks)

TEXT-Fic. 4. Effect of an intravenous injection of fowl semen on interspecific fertility of quail. $O$, No treatment; 9 , injected with fowl semen.

$35 \%$, fertility then increased over a period of 6 weeks, followed by a rapid decline to $20 \%$.

Agglutination tests at the end of the experiment showed that hens with anti- 
body reactions exceeded their counterparts in eight of the twelve fertility tests, but only moderately so. Thus, no relation between fertility and agglutination reactions could be established in this group.

Forty-nine 10-week-old virgin quail hens and twenty quail hens which had been continuously mated to quail males for over a year were tested for circulating antibodies against fowl semen in their plasma. In each case, none was detected. Thus, quail hens could not be shown to have natural antibodies against fowl spermatozoa.

\section{Experiment 2}

The effects of a single intravenous injection of fowl semen into quail females upon interspecific fertility were rapid and pronounced. The average fertility of the controls was $67.7 \%$ while the injected group dropped approximately 10 to $15 \%$ within 1 week after the semen injection, and remained low for the remaining 6 weeks of the experiment (Text-fig. 4).

This difference in fertility was statistically highly significant $(1 \%)$ and establishes that an immunization with fowl spermatozoa can seriously reduce interspecific fertility. Neither egg production nor viability of quail hens were affected by the semen injection.

\section{DISCUSSION}

The results of this study strongly suggest that quail hens develop an immune response to spermatozoa when repeatedly inseminated with fowl semen, and this immune response leads to a decline in interspecific fertility with fowl.

Following prolonged insemination, approximately one half of the quail hens had circulating antibodies against fowl spermatozoa. In general, interspecific fertility of these birds was considerably lower than those in which circulating antibodies were not detected (Text-figs. 1 and 2). The presence of the circulating antibody must have been the result of the insemination, since virgin or naturally mated quail hens were not shown to have natural antibodies against fowl spermatozoa.

The second experiment, in which quail females were given a single injection of fowl semen, supports the conclusion that an immune response causes a decline in interspecific fertility. The hens which were injected had an almost immediate $10 \%$ reduction in fertility (Text-fig. 4 ).

Haley et al. (1966) found that old quail hens, which had not been previously mated to fowl, showed higher cross-fertility than quail hens of less than 3 months old. In a further study (Haley, 1967), three groups of virgin quail females were tested for the effect of age on interspecific fertility. The youngest birds ( 56 days) had the lowest fertility; the intermediate age group (287 days) had intermediate fertility; and the oldest group (517 days) had the highest fertility. Thus, the decline in interspecific fertility in the present experiment cannot be a function of age, but must be attributed to the repeated inseminations.

Intraspecific matings also show a decline in fertility with continuous mating. In fowl, a decline in fertility with prolonged mating is accompanied by in- 
creased levels of serum antibodies against semen (Wentworth \& Mellen, 1964). In natural intraspecific matings of the quail populations used here, quail hens drop from an initial $75 \%$ fertility at 9 weeks of age to about $60 \%$ when they are 40 weeks old (Abplanalp, 1967). However, it has also been shown that old virgin females have lower fertility when mated to quail males than do young virgin females (Woodward \& Abplanalp, 1967). Thus, fertility appears to decline in natural matings of birds due to physiological changes possibly associated with age, and perhaps additionally by anti-spermatozoa immune responses.

The decline in fertility in interspecific matings of fowl and quail is associated with continuous insemination, since old virgin quail females have higher fertility with fowl than do young virgin quail. This suggests that the decline in fertility in interspecific matings is mainly an immunological response.

Perhaps all birds in interspecific matings produce some localized response in the lymphatic system of the oviduct, possibly in the form of sessile antibodies which inactivate spermatozoa in the oviduct and reduce interspecific fertility. This would account for the observation that the terminal fertility of most, if not all, birds was low. The quail hens in which circulating antibodies could not be detected also showed a decline in fertility with continuous interspecific mating (Text-figs. 1, 2 and 3). The decline in interspecific fertility was slower in this group, but the terminal fertility was usually as low as those females which did have antibodies.

Quail females which developed a high degree of immunity early in the insemination period also developed circulating antibodies. These circulating antibodies might possibly inactivate spermatozoa in the sperm nests of the oviduct or perhaps the antibodies might enter the oviduct along with egg albumin proteins and inactivate spermatozoa as they ascend the oviduct. Birds which did develop antibodies in their plasma had much lower interspecific fertility initially than did those which failed to demonstrate such antibodies.

\section{REFERENCES}

Abplanalp, H. (1967) Genetic studies with Japanese quail. Zü̈hter, 37, 99.

HALEY, L. E. (1967) Studies on the control of hybridization between chickens and Japanese quail, p. 79. Doctoral thesis, University of California, Davis.

Haley, L. E., Abplanalp, H. \& Enya, K. (1966) Selection for increased fertility of female quail when mated to male chickens. Evolution, $20,72$.

Lamoreux, W. F. (1940) Spermatozoal antibodies and infertility in fowl. F. exp. Zool. 85, 419.

MaCARTNEY, J. L. (1923) Studies on the mechanism of sterilization of the female by spermatoxin. Am. F. Physiol. 63, 207.

TyLeR, A. (1961) Approaches to the control of fertility based on immunological phenomena. F. Reprod. Fert. 2, 473.

Wentworth, B. G. \& Mellen, W. J. (1963) Effects of spermatozoal antibodies and methods of insemination on the fecundity of White Leghorn females. Poultry Sci. 42, 1317.

WeNTWORTH, B. C. \& MELLEN, W.J. (1964) Effects of spermatozoal antibodies and method of insemination on the fecundity of domestic hens. Br. Poult. Sci. 5, 59.

Woodard, A. E. \& AbPlanalp, H. (1967) The effects of mating ratio and age on fertility and hatchability in Japanese quail. Poultry Sci. 46, 383. 